\title{
Teaching For Understanding: Spotlighting the Blythe and Associates Pedagogical Model
}

\author{
Charles Kivunja \\ University of New England \\ ckivunja@une.edu.au
}

\begin{abstract}
This paper explains what we mean by understanding, particularly in order to achieve deep learning. To so do, the paper initially reviews the relevant literature produced by some of the major thinkers in the field of assessment and measurement. It places special emphasis on The Teaching for Understanding Framework developed by Tina Blythe and Associates which challenges standard practices regarding student evaluation. The paper then uses this model to discuss several strategies that we can use to teach for understanding. Finally, the paper concludes by articulating that while there is no one way to teach for understanding, the use of well researched frameworks offers opportunities for pedagogues to effectively teach in ways where goal setting and evaluation can be applied in order to achieve a deep understanding of the curricula topic under consideration.
\end{abstract}

\section{Introduction}

\subsection{Purpose, Scope and Methodology of this Paper}

Pedagogy abounds with instructional models designed by leaders in the field to facilitate effective teaching and active learning. For example, in Teaching, Learning and Assessment, Kivunja (2015a) reviews many of these models. This diverse review includes the John Locke (1632 - 1704) Tabula Rasa model, Burrhus Skinner's (1953) Behaviorist model, Piaget's (1923) Cognitivist model, Vygotsky’s (1929) Social Constructivist model, Siemens' (2004) Connectivist model, Dunn and Dunn's (1978) model, Kolb and Wolf's (1984)model, and Honey and Mumford's (1982) Learning Styles model, Bloom (1956) Cognitive Taxonomy model, Fink’s (2003) Significant Learning model, the Biggs and Collis' (1982) SOLO model, and Gardner's (1983) Multiple Intelligences model. In Using De Bono's Six Thinking Hats Model to Teach Critical Thinking (Kivunja, 2015b) explains the ways in which a well documented model can be used to teach critical thinking and problem solving to $21^{\text {st }}$ century learners. Further, in Exploring the Pedagogical Meaning and Implications of the 4Cs Super Skills model (Kivunja, 2015c) illustrates how Bruner's 5E Instructional model improves teaching and understanding in what he has called "The New Learning Paradigm" (Kivunja, 2014, p. 40). When one considers the number of models of learning which are frequently cited in many international publications, it is rather surprising that the Blythe and Associates (1998) model on Teaching for Understanding, initially developed at the

Cultural and Pedagogical Inquiry, 2015, 7(1), pp. 84-99

ISSN 1916-3460 @ 2015 University of Alberta

http://ejournals.library.ualberta.ca/index.php/cpi/index 
Harvard Graduate School of Education in 1988, does not feature more prominently in the relevant literature. This paper reviews the recent literature related to models of teaching, highlights the key tenets of the Blythe and Associates model, and further articulates strategies which should enable pedagogues to teach for understanding.

\section{Literature Review}

\subsection{What is Understanding?}

David Perkins, (1998a) e.g. states that:

Good answers to this question are not at all obvious. ... In summary, understanding is being able to carry out a variety of actions or performances that show one's grasp of a topic and at the same time advance it. It is being able to take knowledge and use it in new ways. (pp. 12-13)

As defined this way understanding is not just knowing something, or being able to re-tell what has been taught. It is more than that and represents what Kivunja (2015a) refers to as deep learning. He asserts that understanding may be regarded as:

...the learning process in which learners engage in critical analysis of new ideas that they encounter, link those ideas to concepts and principles that they already know, and through this process gain an understanding and long-term retention of concepts and ideas so that they can then apply them in problem solving in new contexts. This way, deep learning improves understanding and enables application of what is learnt for life. (p. 286)

From this definition, it is clear that deep understanding calls for observable demonstrations or performances of high intellectual quality on the part of the learner. The learner engages in higher-order critical thinking and construction of knowledge, and the application of that knowledge in new contexts. For example Marton and Saljo (1976) found that when students were engaged in learning which led to deep understanding they considered the significance of what they were learning and tried to figure out what it really meant. As a result of this process, they were able to interpret the content in their own way, by integrating the new information with what they already knew. The emphasis in deep understanding is on enabling learners to be able to use what they are taught in new ways that make sense when applied to their daily lives. Such understanding involves what Bloom (1956) calls higher-order cognitive processing, i.e. it requires learners to be able not only to apply what they have learnt but to also be able to analyze, evaluate and create new products, in terms of Knowledge, Skills and Attitudes (KSAs) of their own. 


\subsection{What is Teaching for Understanding?}

Teaching for understanding tries to enable learners to develop a good grasp of what they are taught in order to be able to transfer the KSAs to make sense of new experiences. It aims to lead to understanding which is not just routine memorization (Entwistle, 2000) but one which makes students grasp what they have been taught and try to figure out what it really means in the 'big picture'. Understandably, such learning is not a piecemeal, fragmented process, but is a holistic, integrative process. Accordingly, the students involved take what they have been taught and use their own prior learning, and frames of reference to construct individual meanings within the specific contexts of their world views. They achieve this by integrating the new KSAs from the formal curricula with what they already know. This enables them to deepen their schema and to extend their Zone of Proximal Development (Vygotsky, 1929). Biggs (2006) explains that when students have gained deep understanding they are able to improve their capacity to create new knowledge by themselves. Meyers and Nulty (2008) say that such understanding occurs when students are engaged in authentic, real-world learning experiences. Authentic learning is interesting, challenging and at the same time, it is motivational, and concentrates on involving higherorder cognitive processing.

Although, to achieve understanding is a desirable outcome in all pedagogical constructs, this objective may not always be achieved. The explicit and implicit reasons for this learning phenomenon are well articulated by The National Academy of Sciences (NAOS, 2000) in Washington DC, comprising experts from the Committee on Developments in the Science of Learning, the Committee on Learning Research and Educational Practice, as well as the Commission on Behavioral and Social Sciences and Education, National Research Council, who completed a major educational learning project, and subsequent report entitled, How People Learn. The report asserts that:

...students often have limited opportunities to understand or to make sense of topics because many curricula have emphasized memory rather than understanding.

Textbooks are filled with facts that students are expected to memorize, and most tests assess students' abilities to remember the facts. (NAOS, 2000, pp. 8 -9)

\section{Analysis of The Blythe and Associates Teaching for Understanding Model}

Blythe and Associates (1998) work on their Teaching for Understanding Project produced a model with the following four components: (1) An Overarching Generative Topic, similar to the sky, which encompasses the other three elements: (2) Understanding Goals, (3) Performance of Understanding, and (4) Ongoing Assessment [See Figure 1]. 
Each of the four elements is discussed briefly below.

\subsection{An Overarching Generative Topic}

The model identifies as key the choice of an overarching topic. The overarching generative topic bestrides all the other three elements of the model. It has connections which represent a cross-curricular, integrated approach to the search for understanding, so that students engage with processes that reside in more than one Key Learning Area (KLA). It is a topic that is not only interesting to students and the teacher, but also has multiple connections between what is being taught in the topic and students' real life experiences beyond school. The topic has a high authenticity factor in that what is taught has significance in the lives of students outside the classroom and connects easily to what the students are familiar with outside their school lives. Additionally, an overarching generative topic lends itself to the inclusion of a broad range of resources which students can access and utilize to enhance their understanding of the topic from the perspectives of formal curricula multiple KLAs. The overarching nature of these important topics means that they "should form the core of the curriculum" (NAOS, 2000, p. 18).

\subsection{Understanding Goals}

From the overarching generative topic, a central focus for each lesson needs to be articulated in the form of a specific goal or goals that are to be achieved from a particular learning experience. The goals can be either short-term, in which case they specify what the learners are to understand by the end of a lesson; or long term, specifying what learners need to understand over a prolonged period of study, such as a trimester or year.

\subsection{Performances of Understanding}

Performances of understanding are the activities which "engage students in performances that demonstrate and develop understanding of the unit or course" (Perkins, 1998b, p. 21). These performances start with relatively simple activities, based on information learners are given by the teacher, or are drawn from their textbooks. As students engage with these activities they gradually move to more demanding tasks, such as explaining in their own words, what they have learnt, or read about in their prescribed texts. Their performance is a demonstration of understanding and they can then move on to extending their learning by asking open-ended, higher-order, (Anderson et al., 2001), 'what if' types of questions. Such questions deliberately encourage further speculation, inferences, and extrapolation from the key learning sources about similar but different ideas or related topics. As the students extend their understanding they can then move on to developing progressively even more robust and sophisticated levels of analysis, evaluation, and 
eventually, production of their own representations to depict significant aspects or deep learning concerning the generative topic.

\subsection{Ongoing Assessment.}

The emphasis of assessment in the Blythe et al Teaching for Understanding Framework, under consideration, is on formative rather than summative assessment. While the latter is the traditional type of assessment used primarily for accountability and to assess how learners have achieved specific outcomes at the end of a learning period (Broadfoot, 2009); the former is used to provide information which helps students to know how they are performing and how they can improve their learning outcomes (Black \& Wiliam, 2009). These differences are articulated very well by Bloom, Madaus and Hastings (1971) when they say that:

The main purpose of formative observation ... is to help both the learner and the teacher focus upon the particular learning necessary for movement to mastery. On the other hand, summative evaluation is directed toward a much more general assessment 


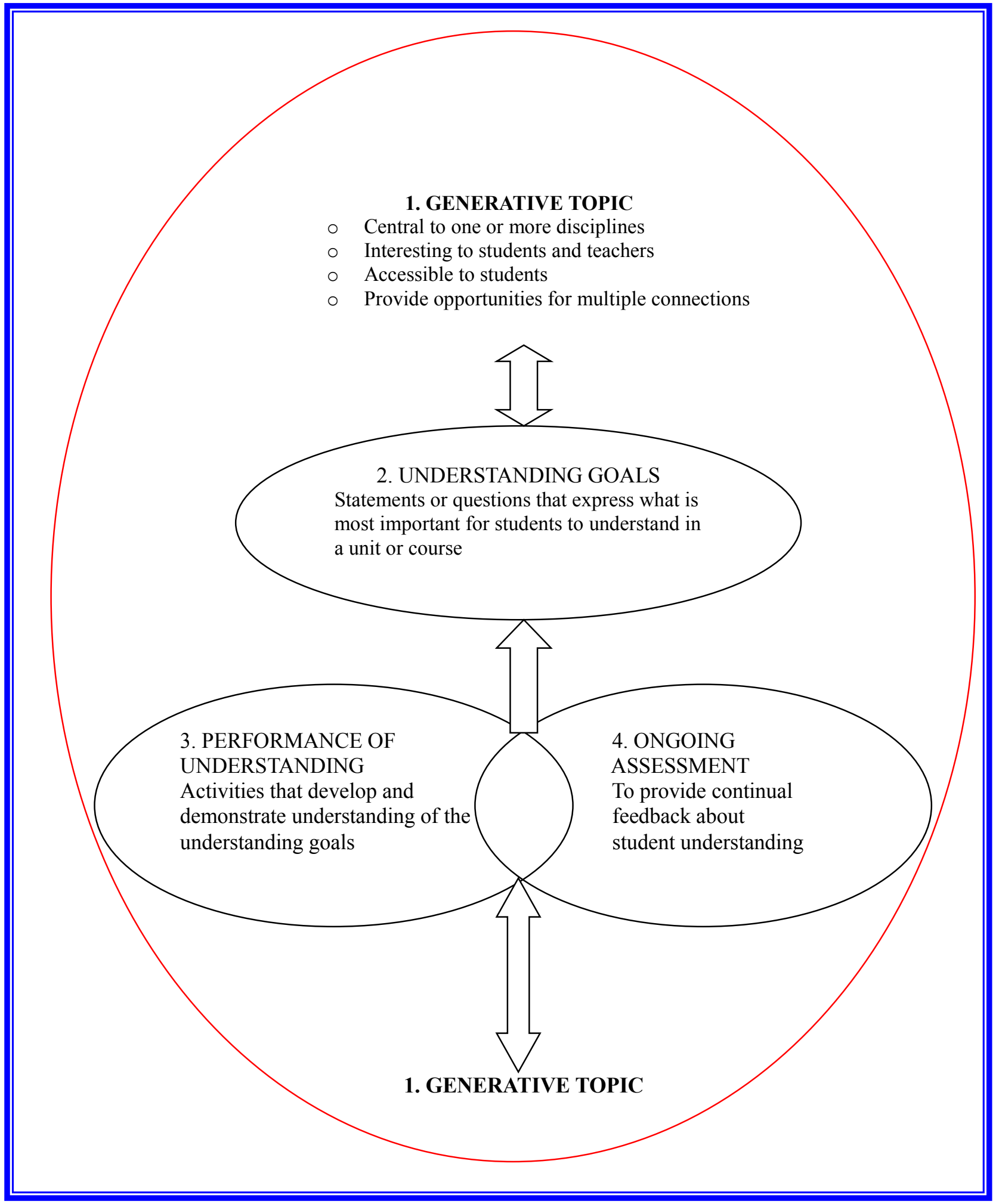

Figure 1: The Blythe and Associates Framework: Teaching for Understanding Source: Blythe \& Associates (1998), p. 19. 
Finally, the Framework advocates frequent provision of feedback to students which enables them to reflect on their performance and thus gives them opportunities to improve throughout the process of learning and instruction.

\section{Teaching Strategies to Facilitate Ways of implementing Blythe et al's, 'Teaching for Understanding Model/Framework'}

\subsection{Developing a Generative Topic}

In this element of the model, Mansilla, James and Jaramillo (1998) provide a range of strategies that teachers can use to determine the generative topic or topics for the unit they are teaching. They emphasize that this step is necessary because "our students have so much to learn - and so little class time in which to begin to learn it" (p. 25). Kivunja (2015a) refers to this phenomenon as "the rather crowded curriculum that involves many key learning areas that must be covered" (p. 161). Essentially, the well documented strategies identified below, help the instructor to determine exactly what KSAs are to be taught in a specific unit or course.

To determine the overarching topics to be taught, the Framework advocates identifying a hierarchy of strategies with accompanying themes for investigation. The themes are then grouped into larger concepts which will be adopted in the subsequent exploration and explication of the specific topics/issues and concepts. The themes can be seen as 'the big picture notions' in which all aspects of the key learning experiences will be embedded. We remember that the concepts and ideas need to be developed in sufficient depth and breadth, so as to give learners the opportunities to gain a far deeper comprehension of concepts and ideas (Marton \& Saljo, 1984) under consideration. Particularly, concepts, as mentioned before, which have significance to students' lived experiences, inside and outside of schools and classrooms. In Australia, the strategies align well with two instructional dimensions: the intellectual quality dimension as well as, the significance dimension of the Quality Teaching Model for New South Wales Public Schools (DET, 2003). The policy document also, supports one of the key tenets of this article's thesis. It advocates linking what the children learn in class with their lives after school. It states that such connections are significant tools to encourage deep learning for understanding. Furthermore, the policy document asserts strongly that instructional strategies characterized by intellectual quality produce “... deep understanding of important, substantive concepts, skills and ideas, [and] ... treats knowledge as something that requires active construction and [allows] students to engage in higher-order thinking to communicate substantively about what they are learning” (NSW-DET, 2003, p. 9). Regarding the significance dimensions, the policy document indicates that strategies which make learning meaningful 
and important to students, by drawing clear connections with students' prior knowledge and identities, with contexts outside of the classroom, and with multiple ways of knowing or cultural perspectives.

Mansilla, James and Jaramillo (1998) include the following strategies to help design a generative topic. (i) Brainstorming and designing a concept map that helps to identify key concepts, issues, and the ideas that interconnect them. (ii) Integrating the specific topic with others so that a cross-curricular or, multidisciplinary KLAs, and/or integrated approach is developed. (iii) Coming up with a topic that interests the students and the teacher, as well. This requires that you know your students quite well. For instance, that you know what they like, what they enjoy, what they like debating, and what issues evoke their strong opinions. (iv) Choosing a topic for which there is a wide variety of resources, available in the public domain. (v) Selecting ideas from the original concept map which have the greatest connections (within and between curricula disciplines). Special attention is given to concepts/issues which are open to analysis from different perspectives. (v) Researching the topic: Instructor and students research the topic well, so as to identify the inherent big ideas that need to be explored, explained and evaluated. (vi) Allowing the right amount of time for the students to: engage deeply with the learning activities, and explore the ideas and interconnections across KLAs to eventually and hopefully achieve an in depth understanding of the significant aspects of the topic/unit under study.

\subsection{Helping Students to Understand the Learning Goals}

Outerbridge (1998) says that the learning goals "identify the concepts, processes and skills that we most want our students to understand" (p. 44). He discusses them analogously like a roadmap that helps us plan where we want our students to go and how to travel on this intellectual journey in order to get there. The learning and understanding goals might be either or both, short or long term.

In order for teachers to help students understand the learning goals, Outerbridge (1998), outlines a wide range of strategies including the following:

(i) Draw on the views and research of experts who inform the unit being studied.

(ii) Draw on personal, professional experience and work to identify what instructional strategies, in the past, helped children to focus on what they needed to study.

(iii) Clearly articulate what is most interesting and rewarding as a result of completing the task. Such clarity in explanation is essential to help the children grasp what is required of them (Land, 1987).

(iv) Specify what will be understanding goals for a unit and then for the course. Articulate a clear focus of the unit or course and a well-defined closure as it concludes. Seek the assistance of 
academic colleagues to critique the understanding goals you want your students to pursue. Talk to your students about the understanding goals at the start of the unit and frame the understanding goals either as categorical statements or questions of understanding. These typically take the form: "Students will develop their understanding of" or be able to describe "What are the important similarities and differences among..." (Outerbridge, 1998, p. 44). However, having articulated learning goals clearly at the start of the unit, it is important to revisit and let the overarching understanding goals evolve as the children engage with the learning and explore new dimensions of the questions, ideas and concepts.

(v) As the students extend their learning for understanding, make sure that the unit-long goals continue to relate to the overarching understanding goals, the generic topic, the performance for understanding that was planned for the unit and assess the children's progress as your teaching for understanding progresses and their understanding develops.

Along this journey give students a lot of opportunities for self-explanations (Brown \& Armstrong, 1984), so that they can participate in inductive and deductive explanations (Sternberg, 2009) to demonstrate to the teacher and to their peers the depth of understanding achieved. The next section, examines key strategies which are helpful tools to develop learners academic performances.

\subsection{Developing Performances of Understanding: Comprehensive Strategies}

Gould (1998), for example, presents the analogy of types of hands-on experiences needed to prepare for the acquisition of measureable competencies which are demonstrated to the examiner in order to pass a motor vehicle driving test. Just as no one would not expect to learn how to drive a car through simply reading about the skills needed and listening to lectures from driving instructors, neither should we expect our students to learn for understanding without engaging in observable competency performances. Gould strongly asserts, "Without actual practice driving a car under a variety of conditions, we cannot learn to drive well and safely. Students learning in school settings need the same kinds of experiences" (p. 56). In agreement with leaders in the field regarding the value of creating a teaching- learning environment in which authentic learning experiences are gained through providing hands-on rich learning tasks, (such as the ones described by Flewelling and Higginson, 2002), Gould states unequivocably, that developing performances of understanding should give learners opportunities to extend the information they are given. Demonstrations occur through applying, analysing, extrapolating and extending what they have learnt, to date. Accordingly, students can extend their learning by being able to demonstrate new ways of thinking and doing things. Interestingly enough, the strategies she advocates align well with Kivunja's tools for creativity and innovation which are much in demand particularly in this digital age (Kivunja, 2015c). 
Gould suggests several strategies to help students engage in substantive learning and to demonstrate measureable performance indicators of achieving different levels of understanding. We list Gould's strategies as follows:

1. A starting strategy is to encourage students to learn not for rote memory,or recall just to pass tests which are related to what they are learning, but to learn for understanding, and where possible to relate information to real life issues.

2. List the key concepts/ideas to be studied.

3. Outline clearly what the students stand to gain by learning the concepts/ideas and, then brainstorm with the students their suggestions for assessing possible performance indicators.

4. Help students to distinguish the importance of what they are to learn, and to identify any differences between what they are to learn and what they have already learnt. As importantly, help them to understand the rationale for learning the key concepts/ideas identified.

5. “Ask [yourself], Why do I want students to do this" (Gould, 1998, p. 66). Both Bruner (1966) and Gould emphasise the need to maximise students participation in learning through giving them activities that engage their intellectual faculties and challenge their understanding as a means of enhancing their performances of understanding.

6. Learners should be made aware of how one set of activities relates to the others identified, and where possible how they relate to issues and concerns in the real world.

7. Articulate how the performances for understanding support the learning goals identified for each unit.

8. Students should be given opportunities to: apply what they have learnt; explore problerms involved, and debate alternative approaches to solving problems identified.

9. When all this is done, students should be given the opportunity to complete learning achieved to date, by performing individual project activities which specify understanding of the major issues and concerns in the specific topic.

10. The assessment activities should require them to apply what they have learnt to new contexts so as to demonstrate their understanding of the topic. This means that the assessment tasks they complete can be observed by the instructor. Students furthermore are given opportunities to publicly display key concepts, issues et al they have learnt to date.

11. As the students engage in their performances of understanding, the instructor provides feedback which helps them to improve on their performances of understanding, and as well, provides insights which help them to make connections between different aspects of the unit and between 
the performances and the understanding goals. (Further details in the assessment process can be accessed by contacting the author directly).

12. The performances should be placed in a specific sequence so that students are engaged with them throughout the unit in question. The sequencing can benefit from being well structured in the following manner, to: (i) consist of introductory performances which gauge students' current understanding of the topic, (ii) introduce guided inquiry performances which give students opportunities to investigate what they consider important aspects of the topic, and (iii) orchestrate culminating performances by the students, which are more complex and call for synthesis of the key concepts and issues, et al so as to provide a logical conclusion. Accordingly, the concluding activities synthesize key learnings, in innovative and creative ways.

It is important for the teacher/instructor to be present in what Gould (1998) calls the role of a "floating coach" (p. 67), who monitors students progress, clarifies misunderstandings and determines what needs to be brought to the attention of all students in a "whole-class discussion" (Kivunja, 2015a, p. 145) or “whole-class explanation" (Kivunja, 2015a, p. 166).

To encourage students to engage more fully and deeply with the learning tasks, the instructor/coach asks the students questions which give them opportunities to explain their learning and to give reasons for their understanding. It is also vitally important to let the students know what parts of their performances of understanding will be assessed; how they will be assessed; and the specific assessment rubric tro be used. Gould (1998) also recommends giving students opportunities for self-assessment, peer assessment and opportunities to make revisions to their proposed final performances of learning, i.e. before their grand finales. Whether as embodied demonstrations and submissions of key significant understandings, using the fine and performing arts, or the more traditional forms/formats for showing understanding.

\subsection{Utilizing Ongoing Assessments and Feedback}

In their contribution to the Teaching for Understanding Framework Bondy and Kendall (1998) argue that assessment should be used not just for evaluation of what students have learned. As well, assessment represents "a substantive contribution to learning. ... It needs to inform students and teachers both about what students currently understand and about how to proceed with subsequent teaching and learning” (p. 71). Accordingly, assessment should be used for formative rather than purely summative purposes (as explained earlier). Therefore, assessment is not simply "the process that monitors students' learning progress" (Brady \& Kennedy, 2009, p. 1). Also as discussed earlier, assessment performs at least two functions, (i) as feedback to encourage improvement in students learning; (ii) to allow teachers to improve their teaching techniques and strategies. Clearly then, assessment's functions are not restricted to 
measuring outcomes or representations of 'products of learning.' Indeed, assessment is a vital part of the entire learning process. (See the author for further details). My views are stated as follows:

Assessment is the process of gathering, interpreting, recording and providing teachers' and students' information about where children are in their responses to an educational task, or in gaining knowledge and skills. Children should have nothing to fear about assessment; it is good for the children's learning as well as for the benefit of the training teachers. (Kivunja, 2015a, pp. $75-76$ )

In grouping the important strategies that can be used to implement ongoing assessment within two large categories Bondy and Kendall (1998) outline their recommendations in the following manner.

*Make sure that the criteria for assessing each task are clearly explained to all students, especially as the students start to engage with the task.

*The criteria should directly relate to the learning outcomes and should be made explicit to students.

* It is a good idea to develop such criteria with the students.

* Concerning feedback: it should be given to students frequently. (As indicated earlier, it should indicate limitations, areas for improvement, and strengths. Students and teacher(s) are to be involved, and finally, feedback should be used to improve teaching).

\section{Conclusion}

Given that three distinguished researchers (Howard Gardner, David Perkins and Vito Perrone) at the Harvard Graduate School of Education in 1988, as well as, many teachers, researchers and scholars, all worked on the project which was published by Tina Blythe and Associates (1988), it is rather surprising that this educational model has received relatively little application in pedagogical circles. The model appears to address a very cardinal question in pedagogy, namely, how can we teach and assess in a way that facilitates deep understanding by our students? This question is so fundamental to authentic pedagogy that any good framework that helps us to address it deserves serious consideration by researchers, students and pedagogues alike. I like the idea of starting with an overarching topic that bestrides everything else done to complete a unit. But perhaps the terminology used, that of a generative topic, might put readers off as this doesn't appear to be a common term in pedagogy. However, the framework outlines quite well what a generative topic looks like. The element of the model that is labeled understanding goals appears to represent well what most jurisdictions refer to as learning outcomes. Performance of understanding is one way to emphasize that students need to be able to demonstrate that 
they have really understood something deeply and so it should be a good aspiration for learners and teachers alike. As well, ongoing assessment would be better articulated as formative assessment since it is possible to have ongoing assessments that are ex-post and summative in nature. For each of the four elements of the model, the framework presents a range of plausible strategies that can be applied to enhance teaching for understanding. Since teaching for understanding is a rather lofty and elusive goal, there is no silver bullet to hit its bull's eye. Instructional models, such as the one reviewed in this paper, appear to support effective pedagogical practice towards achieving this goal. 


\section{References}

Anderson, L. W., Krathwohl, D.R., Airasian, P.W., Cruickshank, K. A., Mayer, R. E., Pintrich, P. R., Raths, J. \& Wittrock, M.C. (2001). A Taxonomy for Learning, Teaching, and Assessing: A Revision of Bloom's Taxonomy of Educational Objectives, (Abridged Edn), New York: Longman.

Biggs, J. \& Collis, K. F. (1982). Evaluating the Quality of Learning: The SOLO Taxonomy (Structure of the Observed Learning Outcomes), New York: Academic Press.

Biggs, J. (2006). Teaching for Quality Learning at University, $2^{\text {nd }}$ Edn, Maidenhead: Open University Press.

Black, P.J. \& Wiliam, D. (2009). Developing the Theory of Formative Assessment, Educational Assessment, Evaluation and Accountability, Vol. 21(1), pp. 5 - 31 .

Bloom, B. H. (1956). Taxonomy of educational objectives, Handbook 1: Cognitive domain, New York: David Mackay Co.

Bloom, B. S., Madaus, G. F. and Hastings, J. T. (1971). Handbook on Formative and Summative Evaluation of Student Learning, New York: McGraw-Hill.

Blythe, T. \& Associates. (1998). The teaching for understanding guide. Jossey-Bass, San Francisco, CA.

Bondy, C. E. \& Kendall, B. (1998). Ongoing assessment. In Blythe, T. \& Associates, The teaching for understanding guide, (pp. 71 - 88), San Francisco, CA: Jossey-Bass.

Broadfoot, P. (2009). An Introduction to Assessment, New York: Continuum International Publishing Group.

Brown, G. A. \& Armstrong, S. (1984). Explaining and Explanations. In E.C. Wragg (Ed). Classroom Teaching Skills, pp. 121 - 148, London: Croom Helm.

Bruner, J. S. (1966). Toward a Theory of Instruction, Cambridge: Harvard University Press.

Dunn, R. \& Dunn, K. (1978). Teaching Students Through Their Individual Learning Styles, Reston, VA: Reston.

Fink, L. D. (2003). Creating Significant Learning Experiences: An Integrated Approach to Designing College Courses, San Francisco: Jossey-Bass.

Flewelling, G. \& Higginson, W. (2002). A Handbook on Rich Learning Tasks: Realising a Vision of Tomorrow's Classroom, Ontario: Centre for Mathematics, Science and Technology Education, Queen's University.

Gardner, H. (1983). Frames of Mind: The Theory of Multiple Intelligences, New York: Basics Books. 
Gould, D. (1998). Performances of understanding. In Blythe, T. \& Associates, The teaching for understanding guide, (pp. 55 - 70), San Francisco, CA: Jossey-Bass.

Harlen, W. \& Deakin-Crick, R. (2002). A Systematic Review of the Impact of Summative Assessment and Tests on Students' Motivation for Learning, London: EPPI-Centre, Social Science Research Unit, University of London Institute of Education.

Honey, P. \& Mumford, A. (1982). The Manual of Learning Styles, Maidenhead: Peter Honey.

Kivunja, C. (2014). Innovative Pedagogies in Higher Education to Become Effective Teachers of 21st Century Skills: Unpacking the Learning and Innovations Skills Domain of the New Learning Paradigm, International Journal of Higher Education, Vol. 3(4), pp. 37 - 48.

Kivunja, C. (2015a). Teaching, Learning and Assessment: Steps towards creative practice, Melbourne, Vic: Oxford University Press.

Kivunja, C. (2015b). Using De Bono's Six Thinking Hats Model to Teach Critical Thinking and Problem Solving Skills Essential for Success in the 21st Century Economy, Creative Education, Vol. 6 (3), pp. 380-391.

Kivunja, C. (2015c). Exploring the Pedagogical Meaning and Implications of the 4Cs "Super Skills" for the 21st Century through Bruner's 5E Lenses of Knowledge Construction to Improve Pedagogies of the New Learning Paradigm, Creative Education, Vol. 6 (2), pp. 224-239.

Kolb, D. A. (1984). Experiential Learning, Englewood Cliffs, NJ: Prentice Hall.

Land, M. L. (1987). Vagueness and Clarity in the Classroom. In T. Husen \& T.N. Postlethwaite (Eds), The International Encyclopaedia of Teaching and Teacher education, (pp. 292 - 397), Oxford: Pergamon Press.

Mansilla, V. B., James, P. \& Jaramillo, R. (1998). Generative topics. In Blythe, T. \& Associates, The teaching for understanding guide, (pp. 25 -34), San Francisco, CA: Jossey-Bass.

Marton, F. \& Saljo, R. (1976). On Qualitative Differences in Learning: Outcome andProcess, British Journal of Educational Psychology, Vol. 46, pp.4-11.

Marton, F. \& Saljo, R. (1984). Approaches to Learning. In F. Marton, D. Hounsell \& N. J. Entwistle (Eds), The Experience of Learning, (pp. 36-55), Scottish Academic Press, Edinburgh. http://dx.doi.org/10.1037/0033-2909.126.6.910

Meyers, N. M. \& Nulty, D. D. (2008). How to use (five) Curriculum design Principles to Align Authentic Learning Environments, Assessment, Students' Approaches to Thinking and Learning Outcomes, Assessment and Evaluation, Vol. 29(6), pp. 687-702. 
NAOS. (2000). How people learn: Brain, mind, experience, and school. Washington, D.C: National Academy Press.

NSW-DET. (2003). Quality Teaching in New South Wales: Discussion Paper, Sydney: DET Professional Support and Curriculum Directorate, May.

Outerbridge, D. (1998). Understanding goals. In Blythe, T. \& Associates, The teaching for understanding guide, (pp. 35 - 53), San Francisco, CA: Jossey-Bass.

Piaget, J. (1923). The Language and Thought of the Child, (Translated M. Gabain), London: Routledge \& Kegan Paul.

Perkins, D. (1998a). Understanding understanding. In Blythe, T. \& Associates, The teaching for understanding guide, (pp. 9 - 16), San Francisco, CA: Jossey-Bass.

Perkins, D. (1998b). The teaching for understanding framework. In Blythe, T. \& Associates, The teaching for understanding guide, (pp. 17 - 24), San Francisco, CA: Jossey-Bass.

Siemens, G. (2004). Connectivism: A Learning Theory for the Digital Age, Journal of Instructional Technology and Distance Learning, Vol. 2(1).

Skinner, B. F. (1953). Science and Human Behavior, New York: Macmillan.

Sternberg, R. J. (2009). Cognitive Psychology, Belmont, CA: Wadsworth.

Watson, J. B. (1913). Psychology as a behaviorist views it. Psychological Review, Vol. 20, pp. 158 - 177.

Vygotsky, L. S. (1929). The problem of the cultural development of the child, Journal of Genetic Psychology, Vol. (36), pp. $415-434$. 